\title{
Perceptions of Pakistani Learners of English about Standard British and American
}

\section{English: An Exploratory Approach}

* Dr. Syed Shujaat Ali, Assistant Professor (Corresponding Author)

** Muhammad Ishtiaq, Lecturer

*** Muhammad Shahid, Lecturer

\begin{abstract}
Pakistani learners of English are exposed to the same degree to both the British and the American variety of English language. There is no state policy or direction regarding the preference of one variety over the other in being used for getting education. Overall society and educational institutes are free to adopt or promote any variety that they deem proper. Both the varieties are used extensively, are quite popular, and enjoy sufficient means and reasons to be effective in society. The lack of uniformity in adopting a particular variety leads to multiple problems, including an English variety having features of both American and British English in different degrees, depending on each user's different degree of exposure to both the varieties. For ensuring uniformity and avoiding confusion, the researcher thought it compulsory to make a recommendation for the adoption of a single variety out of the two, based on its suitability and utility. However, the researcher feels it urgent that before making recommendations to the government for the adoption of a single variety, the wishes and predilections of the people of Pakistan have to be considered and the reasons why some prefer British variety and some the American variety have to be identified and assessed. If they preferred a feature of English, then did they know which variety it belonged to and if they knew then why did they like it. In the process, the researcher also strove to find out as to what extent the knowledge of literature and history of the country of the variety, contributed to affecting the preference of the Pakistani people. Data was gathered from sixty-six participants from two universities of Pakistan, namely Kohat University of Science and Technology (KUST) Kohat from the KP Province on the provincial level, and National University of Modern Languages (NUML) Islamabad from the Federal capital, Islamabad, on the federal level; participants were enquired about their approaches, attitudes, and feelings towards the variety of English they preferred and to explain reasons and motives behind the selection/rejection of one or other of the two varieties, through a questionnaire having seven close-ended and three open-ended items.
\end{abstract}

Keywords: Motivation, Standard variety, World Englishes, EFL, TEFL

Introduction

Both the British and the American varieties of English language enjoy sufficient means to be effective in society e.g. Britain has a long history of ruling this land, framing its educational policies, and its school system has been prevalent, dating back to the British rule. On the other hand, due to Pakistan's strategic military and political relationship of alliance with America, there exists widespread cultural invasion from America in the form of the prevalence of its school system, its Hollywood movies, and its other activities inside Pakistan.

There has been a parallel expansion and development in the scope of the English language right from the time of the first establishment and subsequent expansion of the British Empire. English along with the colonizers also became the language of the colonized in different continents of the world like Asia, Africa, Australia, and North America but more particularly in the last two. Naturally due to the influence of the local languages English language in different parts of the world experienced certain changes of lexical, semantic, structural, and formal nature which resultantly led to the emergence of various World Englishes (WE) or, to be more precise, different varieties of English.

* Department of English, Kohat University of Science \& Technology, Kohat

Email: s_shojaat_ali@yahoo.com

** Government College of Management Sciences, Kohat Email: ishtiaqm17@gmail.com

*** Department of English, University of Malakand Email: shahiduom1@ gmail.com 
In this respect, a lot of research studies have been conducted to know and determine the feelings and attitudes toward the different varieties of World Englishes. Many of the research studies conducted in this connection have been motivated by somewhat similar research questions about the preferences or likes/dislikes for the different varieties of US, but researchers have employed different ways and approaches (methods) to answer them. For instance, Tan and Tan (2008), Tokumoto and Shibata (2011), and Bernaisch (2012) frequently surveyed different university students by asking them to rate, in order of preference, the different varieties of WE on Likert scales and closed-ended questionnaires. Similarly, Zhang and Hu (2008), Cavallaro and Chin (2009), Evans (2010), and Hundt, Zipp, and Huber (2015), focused their research by giving the participants open-ended questions and also using recordings rather than simply relying on participants' inadequate knowledge of WE. So these studies have extended our knowledge and understanding of attitudes toward various Wes in different parts of the world. The present study, therefore, focuses on understanding and knowing the attitudes of Pakistani English speakers towards standard British and American variety of English. The significance of the present research is to determine whether Pakistani learners of English are positively disposed of either towards the British or American variety of English. In this study, the researcher seeks to learn:

1. How do Pakistani learners of English respond to the two varieties of Standard English?

2. Do people who are more informed about the history, origin, and development of a language have more positive attitudes towards that variety of language and its people?

\section{Literature Review}

Several researchers of WE have employed close-ended questionnaires, open-ended questions, and recordings to let the participants give their attitudes towards the different WE varieties. For example, Zhang and $\mathrm{Hu}$ (2008) explored the attitudes held towards American, British, and Australian Englishes by interviewing the participants of his study. For this purpose, 30 Chinese Master's and Doctoral students, studying at different universities in the USA, were exposed to listen to the recordings of a native speaker from each of the variety. The study demonstrated that participants were positively disposed towards both British and American varieties of English in all its features whereas they held negative attitudes towards the Australian variety of English. Similarly, Cavallaro and Chin (2009) used recordings to examine the attitudes held towards the two varieties of Singaporean English i.e. Singapore Standard English and Singapore Colloquial English.

Evans (2010) studied the attitudes of Chinese English learners towards the Standard British and American varieties of English. Participants were required to respond to open-ended questions in which a choice was given as to which standard variety of English (British Or American) they would like to adopt as ESL learners. The findings revealed that participants cherished British English for its "pleasantness and politeness," and the American variety of English for its "casualness and modernism" (275-276). Evan's study does not make use of recordings for eliciting the attitudes of participants, instead, she used an open-ended questionnaires in her study.

Hundt, Zipp, and Huber (2015) employed open-ended questions and recordings as well as writing samples, and other data gathering ways and techniques. The basic drive of their study was to know the attitudes of Fijians towards World Englishes, specifically standard British and American varieties. To ascertain the attitudes of the participants, questionnaires were administered to 149 Fijian university students. The questionnaires had four open-ended questions concerning language attitudes and usage. The participants were also required to write a short essay reflecting which English they generally used in their ordinary lives. The findings of these researchers indicated that Standard British English is considered as having the highest prestige among the different varieties of Wes, followed by American, Australian, New Zealand, and South African varieties of English. The only flaw in Hundt, Zipp, and Huber's work was the lack of direct interaction between the individual participant and the researcher for they have relied merely on paper-based questionnaires. Direct interaction between each participant and the researcher ensures greater understanding and clarity in the research process.

Tokumoto and Shibata (2011) explored the attitudes of Japanese, South Koreans, and Malaysians not only towards their respective varieties of English, but also towards Standard American and British varieties of English. After filling in the questionnaire, the participants were asked to answer a series of questions in writing such as 'what they think as the most significant and essential aspect of speaking English' and 'which English variety they generally used for adjudging others'. The 
findings of their work displayed that Japanese and South Korean participants held negative views regarding their respective varieties of English, whereas the Malaysians held positive views and opinions about their variety of English.

Tokumoto and Shibata evaluate and assess the attitudes of their research participants on Likert scales and paper-based questionnaires, but it would have been far better to have used interviews because interview as a method of data collection tool is valued due to its allowance for more natural discussion and wider opportunities for the participants to explain their opinions, feelings, and beliefs. Similarly, Bernaisch's (2012) study which examined the attitude of Sri Lankans towards Wes also confirmed that British English is considered as the most esteemed form of English followed by their regional variety of Sri Lankan English. American English is placed after the Sri Lankan variety of English. No doubt, Bernaisch's study concluded the attitudes of Sri Lankan towards various Wes, but the method is designed in a way that could not capture any attitude beyond the ranked order of preferences and does not allow for multiple value judgments.

Yoshikawa (2005) conducted his study about the perceptions of Japanese students towards US. He came up with somewhat new and interesting results, such as the majority of participants had nurtured contempt for the New Englishes and preferred only the standard variety of English. The only loophole in Yoshikawa's work is that he collected the data merely by administering a close-ended questionnaire. If he had added some qualitative aspect to his work like conducting interviews or focused group discussion or reflective writing by the participants, the results and findings would have been more well-founded, authentic, and worth relying on.

This somewhat brief literature about the attitude of various peoples across the world is indicative of two broad facts. First, there is greater disagreement among the peoples about the acceptance of different varieties of WEs. Not all people equally accept the different varieties of English as equal to the standard variety of British or American English. Surprisingly, the purest does not accept even American English as a standard variety of English. According to the purest, there is only one Standard English namely British English. Secondly, that close-ended questionnaire is a major form of data collection tool when studying the perception of peoples about WEs. Against this, the use of open-ended questions and discussion group allows to understand the attitudes of peoples in greater depth towards WEs. The researcher uses a questionnaire that is comprised of both close-ended as well as open-ended questions. Open-ended questions are used to come up with data that are representative of the participants' attitudes or perceptions in this research study.

\section{Methodology}

The purpose of the present research study is to know and determine the potential factors that influence the attitude of Pakistani learners of English towards the two specific standard varieties of English. Additionally, this precise and brief work tries to explore if factors like information about the history, development, and origin of language or aspects like educations, culture, and personal beliefs inform the attitudes of learners towards the standard varieties of British and American English along with the speakers of these varieties.

\section{Context of the Present Research}

The present study was accomplished at Kohat University of Science and Technology (KUST) Kohat, a public university belonging to Khyber Pakhtunkhwa- one of the four provinces of Pakistan, and National University of Modern Languages (NUML) Islamabad, chosen from among the public sector universities of the federal capital of Pakistan. Only Fresh students of the English Department at both universities having studied the modules of Sociolinguistics and Phonology were selected for the study. From each university, 17 male and 15 female students (32 in total) were engaged for the present study. All the students who participated in this study for data collection purposes were volunteers.

\section{Research Questions}

This study tries to seek answers to the following research questions:

1. How do Pakistani learners of English respond to British and American varieties of Standard English?

2. Do people who are more informed about the history, origin, and development of a language

\section{Participants}

have more positive attitudes towards that variety of language and its people?

In total, 64 participants from the two universities i.e. KUST Kohat and NUML Islamabad, 34 males 
and 30 females, volunteered to be part of the study. All the participants were students of the seventh semester and were pursuing their graduate degrees in the discipline of Linguistics. The learners from two universities had socially, culturally, and financially mixed backgrounds ranging from upper middle class to lower class and hails from both from rural as well as urban locality of the country. The participants were assigned Pseudonyms to ensure their anonymity.

\section{Data Collection}

Data for this study was gathered by using the tool of questionnaire having both close-ended as well as open-ended questions. The questions were about a variety of topics to know the likely influences on attitudes of learners towards the two standard varieties of English i.e. British and American. The questionnaire had seven close-ended and three open-ended questions. The close-ended questions pertained to participants' general background information such as their social, cultural, and educational experiences about the two languages. The three open-ended questions investigated the participants' perceptions and insights towards the speakers of standard British and American English. The open-ended questions were follow- up questions focusing on reasons and causes that make them motivated to choose one or the other of the two varieties of Standard English. These follow-up questions were used to gain a more in-depth understanding and appreciation of the respondents' reactions.

\section{Data Analysis}

For coding, the researcher went through the two categories of questions i.e. close-ended and openended items of the questionnaire (referred to in the Appendix). Themes were carefully recorded from each of the two separate categories. Repeated themes that stood out from the participants' responses in the close-ended and open-ended sections of the questionnaire were labeled. The different categories of questions were related to the background of the participants, their exposure/experiences to the two varieties of Standard English, and their own perceptions/thoughts about these two varieties of English. The following responses were particularly focused on:

$>\quad$ Prior knowledge of the Participants about the two varieties

$>\quad$ The variety of English they heard particularly in college/university from teachers and in media and the variety of English they use at home with family and with colleagues/friends in daily life

$>\quad$ Motivating and demotivating factors in opting one or the other of the two languages

$>\quad$ The influence of their teachers/colleagues, media, or any other event in selecting British/American variety of English.

These responses were focused on due to the possible effects they could have on participants 'perceptions and attitudes regarding the preference for either British or American English which is one of the research questions. The themes gathered from the two sections are previous knowledge about the language, Influence of a teacher/s, or academic subject in a college/university, and Accent, Vocabulary, and Spelling Preferences. The themes gleaned from the participants' responses are presented along with definitions and examples in the following table.

Table 1: Themes, Definitions and Examples

\begin{tabular}{lll}
\hline \multicolumn{1}{c}{ Themes } & \multicolumn{1}{c}{ Definitions } & \multicolumn{1}{c}{ Examples } \\
\hline $\begin{array}{l}\text { Previous knowledge about } \\
\text { the language }\end{array}$ & $\begin{array}{l}\text { Participants' knowledge of } \\
\text { how the language emerged, } \\
\text { developed, and used. }\end{array}$ & $\begin{array}{l}\text { Altaf: I like British English for its rich and } \\
\text { diverse history right from the time of the } \\
\text { Anglo Saxon till its enrichment by the colonial } \\
\text { extension in various parts of the world. }\end{array}$
\end{tabular}

Influence of a teacher/s, or academic subject in a college/university
Through an academic subject taught in a college/university, the participants get familiar with the American/British variety of English or they get knowledge of the differences from a fellow student/s or a teacher/s.
Misbah: While studying at university, our phonology teachers particularly made us conscious about the different pronunciation of American/British English.

Nasreen: I came across the term British, American, Canadian, and Australian English's in my course of Sociolinguistics for the first time. 
Accent, Vocabulary, and Natural liking/inclination for Spelling Preferences
Natural liking/inclination for
the American or British accent, spelling etc.

Umair: The British speak English quite naturally quite unsurpassable by any other variety or nation of the world. The way they tune it, pace it, and pronounce it are superb and worth listening to.

Irfan: I prefer the American accent because it is mostly like our own accent and I like American spelling due to its simplified form.

The major purpose of this section was the presentation of the methodology and evaluation of data identified in the present study. The next section comes up with the findings, limitations, and further discussion of the study.

\section{Findings}

\section{Research Question One: How do Pakistani learners of English respond to British and American varieties of Standard English?}

It was found through a closer inspection of the data gathered from the participants' responses that there was quite a clear difference in perceptions and attitudes of Pakistani learners of English to the British and American standard varieties of English. The responses of the participants were such as can be conveniently divided into two distinct groups. For example, those who were predisposed towards American English had similar motives and those favouring British English had some common grounds for it inside its group. For instance, in response to open question No. 8 of the questionnaire which asked about the motivating factors in using either British or American English, almost $45 \%$ of the participants wrote that they like British English because it is the mother country (point of origin) of English language. According to them all other varieties are merely the by-products of the colonial expansion and cannot be at par with the original. Against this $55 \%$ of the participants opted for American English for various reasons like its extensive use everywhere in the world, better job opportunities, awards of scholarship at American universities, widespread usage in social and electronic media, etc.

The second open-ended research question "which aspect of American/British English such as accent, vocabulary, rhythm, etc. is appealing to you in terms of opting it if you were to use it in everyday life" indicated different tendencies between those who are prone towards the American or British variety of English. Exactly $60 \%$ of the participants declared that the accent of American Standard English matches their native accent of English that is why they prefer it because it is more lucid and understandable for them. $40 \%$ participants thought that they particularly like British Standard English for its unique features of pronunciation (such as dropping of final $/ \mathrm{r} /$ sound when it is not followed by a vowel sound, the clear pronunciation of $/ \mathrm{j} /$ sound in so many words like / stju:.dənt/, 「æt.i.tju:d/ etc. when it is equally neglected in almost all non-native varieties of English including American Standard English. Moreover, they declared that British Standard English is highly formal and academic as far as its vocabulary is concerned, whereas American English tends mostly to be colloquial and informal. Surprisingly, 68\% of the participants demonstrate a preference for the American spelling due to its simplicity whereas $32 \%$ liked British spelling considering it somewhat unique.

The third open-ended question related to the influence of teachers, colleagues, friends, or any other factor in opting British/American English was evenly answered by the two groups of respondents i.e. pro-British and pro-American. They were strongly influenced in their choice either by explicit instructions on the part of their teachers or in some cases they simply like the accent and overall style of speaking of a particular teacher with British or American variety of English. Overall $90 \%$ of participants were influenced either by their teachers (explicitly or implicitly). Many of the participants had developed a taste for American English through widespread listening to it using different online sources. It is worth noting that almost $50 \%$ of participants of those favouring American English responded that their ears are more tuned to the American accent due to large-scale listening to it through social media or YouTube or other online sources. Only 23\% of the participants were influenced by their teachers in selecting British English and seven percent of participants responded that their choice for British English is especially influenced by listening to BBC news and podcasts on the Website of British Council. 


\section{Research Question Two: Do people who are more informed about the history, origin, and development of a language have more positive attitudes towards that variety of language and its people?}

To comprehend the participant experiences, responses from the close-ended questions of the questionnaire (background information questions) were analyzed. Only 57\% of participants ascribed the origins of English Language to England and the remaining 43\% thought that it can be traced both to England and America. Similarly when asked what do they think about the English language used in Britain and America, 70\% responded that it is the same language, 27\% considered them as two different languages whereas only three percent thought it almost the same accept a little bit of variation. There was no split in response to question No.3 which was about the sources that informed them about the differences in British and American English. Almost all of them attributed their firsthand knowledge firstly to their teachers and secondly to a book or an article. Only five percent attributed their knowledge of British and American English to a fellow student.

There was a noticeable split among the participants in response to question No 4 that asked which variety of English they heard from their respective teachers in college/university. The responses were quite varied such as 33\% opted for British English, 35\% for American English, and $32 \%$ for both the varieties. Similarly, in response to the question of which variety of English do they use when communicating with teachers/colleagues, friends, and family in everyday life there was a sort of mixed response with no clear tendency towards American or British English. Among the participants 45\% answered American English, 33\% said that they use British English and 22\% thought that they use a mixture of both the varieties in their daily use.

When confronted to choose from the two alternative vocabulary items of the same meaning (British/American lexical choice) the results were quite unexpected and surprising. For example, almost $77 \%$ of the participants opted the British English lexical item, 13\% chose American and the remaining $10 \%$ chose both the options. Interestingly, all those who had opted for British English in earlier options of the questionnaire accurately opted for the British vocabulary item. Unlike this, 34\% of the participants who opted for British vocabulary items had opted for American English in earlier options of questionnaire.

Similarly, the response to the last questionnaire item asking "which Dictionary of English do they use normally" was a bit in contradiction compared to the responses of earlier items of the questionnaire. For example, almost $42 \%$ of participants used all three dictionaries (Cambridge, Oxford, and Mariam Webster Dictionary), 50\% of participants used only Cambridge and Oxford Advanced Learners Dictionaries, and only $8 \%$ responded that they use only Mariam Webster Dictionary. Again those who opted for British English in earlier responses opted for only Cambridge and Oxford Advanced Learners Dictionaries, whereas those who opted for American English, in earlier responses, used all the three dictionaries equally, with no preference for one over the other.

There was a very clear correlation between the attitudes of participants and their background information about the language they chose as Standard or preferred for their daily use. For example, all the participants that chose British English as Standard or preferred it for use in their daily lives had strong background knowledge about the British and American English. Moreover, they used either Oxford or Cambridge Advanced Learners Dictionary as they considered them more reliable compared to Mariam Webster Dictionary. Against this, participants who were predisposed towards American English ticked all the three dictionaries for use which shows that there is no real difference for them using any of the dictionaries. Similarly, when confronted with the options of alternative lexical items of British and American English, the participants that prefer British English accurately chose British English vocabulary items whereas many of the Participants though earlier chose to prefer American English but were unable to identify it.

\section{Discussion}

From the varied responses of participants in both close and open-ended items of the questionnaire, there emerged clear themes such as previous knowledge about the language, familiarity through media, a teacher/s, and a fellow student/s, in college/university, and Accent favouring. Each of these themes is discussed separately in the following section.

\section{Previous Knowledge about the Language}

From the participant responses of this study the influence of previous knowledge about the language on learners' perception is markedly visible. An average of $33 \%$ of participants who had real 
knowledge about the British and American English come up with consistent answers throughout the entire questionnaire items. They knew British lexical items and they had a clear view which dictionary/s to use unlike those who had a vague sort of understanding of both American and British varieties of English. For example, some of the respondents had chosen in earlier questionnaire items that they prefer American English but when asked to choose a particular lexical item from the two alternative options, they tended to opt for the British English lexical items. Similarly, they use all the dictionaries without having any marked tendency to use a particular dictionary unlike those favoring British English who only used Cambridge and Oxford Dictionaries. The researcher strongly feels if many of the respondents had a clear knowledge of the two varieties they must have had quite a clear attitude (like those 33\% participants who had clear knowledge of the British and American English) towards either the American or British English.

\section{Influence of a teacher/s, academic subject in a College/University}

It became evident from the data that almost all of the participants' perceptions were built and influenced primarily by their teachers and to some extent by an article or books on the same subject in a college/university. This indicates that the participants' attitudes and perceptions must have been more or less positively/negatively influenced the variety of English their teacher/s favoured/disfavoured. For example, 33\% of participants who responded that they heard British English from their teachers in college/university demonstrate consistency in their attitude towards British English such as they chose all the British English lexical items correctly and showed a marked preference for Cambridge and Oxford Advanced Learners Dictionaries.

\section{Accent, Vocabulary, and Spelling Preferences}

Data of the present study indicate that the participants favoured either the American or the British English on account of their preferences for the accent, vocabulary, and orthographic conventions of one or the other of the two varieties. One of the participants presented the point, "I like British English due to its formal and academic temperament and disfavour the American English due to its invariably casual and informal tendency. Another participant has remarked that he hates American English because it is a wilfully corrupted version of Standard British English. Similarly, there was more split among the participants about accent favouring and orthographic conventions of the two varieties of languages in their favouring of British or American English. The majority of the participants favoured American English on account of features of pronunciation that matched their own local and regional accent of English. Likewise, they showed a preference for American English on account of the simplified spelling forms of it. On the other hand, some participants remarked that they like British English for its musicality, non-phonetic quality (its quality of not being spoken the way it is written), and long history. The same participants added that he has to dislike for the American English due to its roughness, lack of originality. Interestingly, some nearly $30 \%$ of the participants that consistently showed a marked inclination and preference for the British English consider these features of pronunciation, vocabulary, and spelling as unique and worth loving about the Standard British variety.

\section{Conclusion}

The results of the present study can be helpful to assist the field of sociolinguistics in providing a more profound understanding of peoples' perceptions and attitudes due to their life experiences and interaction with a particular variety of language. The findings and results of the present study confirm that learners who had deep and extensive knowledge or more commonly experienced a variety of language will have positive attitudes towards that variety. This can be witnessed from the responses of those who favor British English and those who are positively disposed towards American English respectively. Another major conclusion that can be drawn from the study is about the influence of teachers, especially at the college/university level. Almost all the learners from both the universities unanimously agreed that they had been influenced in the selection of British/American English by their teachers. There is a greater likelihood if the learners are given more exposure to one or other variety, then there would have been a greater probability of them having nurtured more positive attitudes towards one and more negative attitudes towards the other variety. It is obvious from the findings of the present study that Pakistani learners of English do respond to British and American English quite differently. Much of their responses are somewhat alike in the sense their attitudes towards the two Standard Varieties of English are strongly affected positively or negatively by their experiences with each one of them. Having more knowledge about a variety or having more 
experience with a variety lets the learners nourish more/less positive attitudes towards that variety of language. This shows that as learners get more accustomed with or gain more awareness of a variety, they grow more and more interested in the variety.

\section{References}

Bernaisch, T. (2012). Attitudes towards Englishes in Sri Lanka. World Englishes, (31)3, 279-291.

Cavallaro, F., \& Bee Chin, N. (2009). Between status and solidarity in Singapore. World Englishes (28)2, 143-159.

Dalton-Puffer, C., Kaltenboeck, G., \& Smit, U. (1997). Learner attitudes and the pronunciation in Austria. World Englishes, 16(1), 118-128.

Evans, B. (2010). Chinese perceptions of Inner Circle varieties of English. World Englishes, (29)2, 270-280.

Hiraga, Y. (2005). British attitudes towards six varieties of English in the USA and Britain. World Englishes, (24)3. 289-308.

Hundt, M., Zipp, L., \& Huber, A. (2015). Attitudes in Fiji towards varieties of English. World Englishes, 34(4). 688-707.

Tan, P. K. W., \& Tan, K. H. (2008). Attitudes towards non-standard English in Singapore. World Englishes, 27(3/4), 465-479.

Tokumoto, M., \& Shibata, M. (2011). Asian varieties of English: Attitudes towards pronunciation. World Englishes (30)3, 392-408.

Yoshikawa, H. (2005). Recognition of world Englishes: changes in Chukyo University students' attitudes. World Englishes, 24(3), 351-360.

Zhang, W., \& Hu, G. (2008). Second language learners' attitudes towards English varieties. Language Awareness, 17(4), 342-347. 